\title{
Sektion Kopf-Hals schreibt Förderpreis aus - jetzt bewerben
}

Die Sektion Kopf-Hals der Deutschen Gesellschaft für Ultraschall in der Medizin (DEGUM) schreibt auch für 2020 den Förderpreis der Sektion aus. Der Preis ist mit 500 Euro dotiert und richtet sich an Wissenschaftler der Kopf-Hals-Sonografie, die sich mit außergewöhnlichen Publikationen oder einer Habilitationsschrift der Kopf-HalsSonografie verdient gemacht haben.
Autoren, die bereits den DEGUM-Preis verliehen bekommen haben, können sich nicht ein zweites Mal bewerben. Es ist jedoch möglich, dass eine abgelehnte Arbeit im Folgejahr erneut eingereicht wird.

Der Antrag ist formlos auf elektronischem Weg unter Anlage der eingereichten Publikation bis zum 30. April 2020 an die DEGUM-Geschäftsstelle (DEGUM e. V.,
Charlottenstr. 79/80, 10117 Berlin, gescha eftsstelle@degum.de) zu richten.

Die Preisverleihung erfolgt während des Treffens der Sektion Kopf-Hals im Herbst 2020. Die Anwesenheit des Preisträgers ist hierbei obligat. Im Rahmen der Preisverleihung wird der Preisträger bzw. die Preisträgerin aufgefordert, die Arbeit in einem Kurzreferat vorzustellen. 